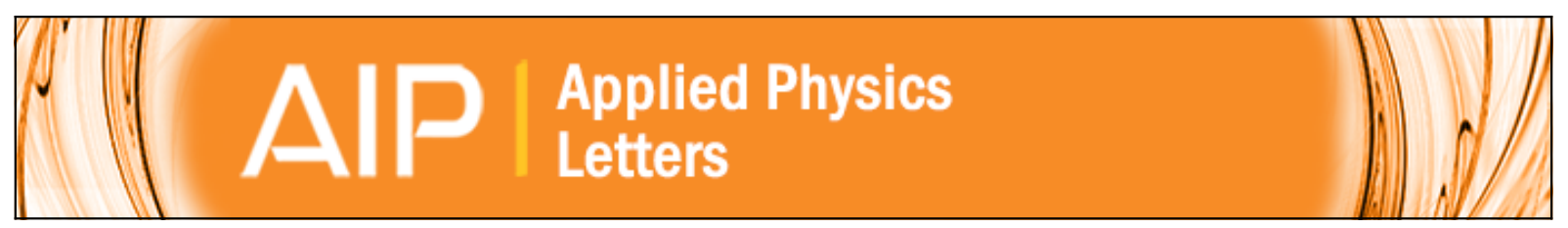

\title{
Thermodynamics and kinetics of defects in Li2S
}

Ashkan Moradabadi and Payam Kaghazchi

Citation: Applied Physics Letters 108, 213906 (2016); doi: 10.1063/1.4952434

View online: http://dx.doi.org/10.1063/1.4952434

View Table of Contents: http://scitation.aip.org/content/aip/journal/apl/108/21?ver=pdfcov

Published by the AIP Publishing

\section{Articles you may be interested in}

The role of electronic and ionic conductivities in the rate performance of tunnel structured manganese oxides in Li-ion batteries

APL Mater. 4, 046108 (2016); 10.1063/1.4948272

Computational characterization of lightweight multilayer MXene Li-ion battery anodes

Appl. Phys. Lett. 108, 023901 (2016); 10.1063/1.4939745

Ultrahigh energy density Li-ion batteries based on cathodes of $1 \mathrm{D}$ metals with $-\mathrm{Li}-\mathrm{N}-\mathrm{B}-\mathrm{N}-$ repeating units in $\alpha-\mathrm{Li}$ $x$ BN2 $(1 \times 3)$

J. Chem. Phys. 141, 054711 (2014); 10.1063/1.4891868

Ideal design of textured LiCoO2 sintered electrode for Li-ion secondary battery

APL Mater. 1, 042110 (2013); $10.1063 / 1.4824042$

Charging-induced defect formation in $\mathrm{Li} \times \mathrm{CoO} 2$ battery cathodes studied by positron annihilation spectroscopy Appl. Phys. Lett. 102, 151901 (2013); 10.1063/1.4801998

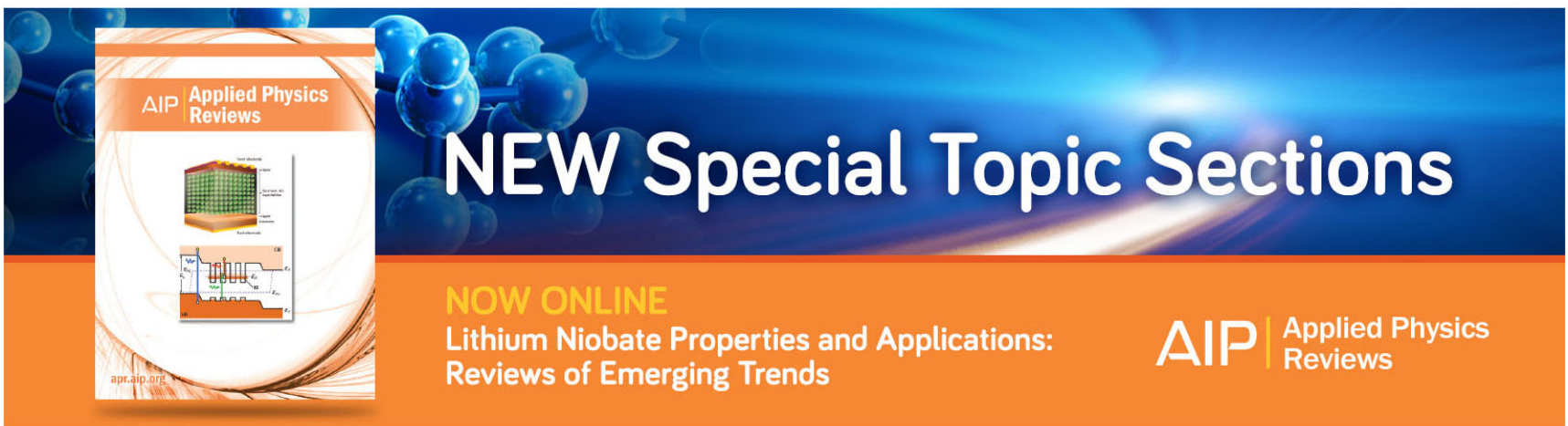




\title{
Thermodynamics and kinetics of defects in $\mathrm{Li}_{2} \mathrm{~S}$
}

\author{
Ashkan Moradabadi ${ }^{1,2}$ and Payam Kaghazchi ${ }^{2, a)}$ \\ ${ }^{1}$ Institut für Materialwissenschaft, Fachgebiet Materialmodellierung, Technische Universität Darmstadt, \\ Jovanka-Bontschits-Str. 2, 64287 Darmstadt, Germany \\ ${ }^{2}$ Institut für Chemie und Biochemie, Freie Universität Berlin, Takustr. 3, 14195 Berlin, Germany
}

(Received 2 December 2015; accepted 11 May 2016; published online 26 May 2016)

$\mathrm{Li}_{2} \mathrm{~S}$ is the final product of lithiation of sulfur cathodes in lithium-sulfur ( $\left.\mathrm{Li}-\mathrm{S}\right)$ batteries. In this work, we study formation and diffusion of defects in $\mathrm{Li}_{2} \mathrm{~S}$. It is found that for a wide range of voltages (referenced to metal $\mathrm{Li}$ ) between $0.17 \mathrm{~V}$ and $2.01 \mathrm{~V}$, positively charged interstitial $\mathrm{Li}\left(\mathrm{Li}^{+}\right)$is the most favorable defect type with a fixed formation energy of $1.02 \mathrm{eV}$. The formation energy of negatively charged $\mathrm{Li}$ vacancy $\left(\mathrm{V}_{L i}^{-}\right)$is also constant, and it is only $0.13 \mathrm{eV}$ higher than that of $\mathrm{Li}^{+}$. For a narrow range of voltages between $0.00 \mathrm{~V}$ and $0.17 \mathrm{~V}$, the formation energy of neutral S vacancy is the lowest and it decreases with decreasing the cell voltage. The energy barrier for $\mathrm{Li}^{+}$diffusion $(0.45 \mathrm{eV})$, which takes place via an exchange mechanism, is $0.18 \mathrm{eV}$ higher than that for $\mathrm{V}_{L i}^{-}$ $(0.27 \mathrm{eV})$, which takes place via a single vacancy hopping. Considering formation energies and diffusion barriers, we find that ionic conductivity in $\mathrm{Li}_{2} \mathrm{~S}$ is due to both $\mathrm{Li}^{+}$and $\mathrm{V}_{L i}^{-}$, but the latter mechanism being slightly more favorable. Published by AIP Publishing.

[http://dx.doi.org/10.1063/1.4952434]

Fundamental understanding of $\mathrm{Li}$ ion transport in solid electrode materials is of particular importance for the development of Li-based batteries $(\mathrm{LiB})$ with high rate capabilities and high capacities. The process of $\mathrm{Li}^{+}$transport has thus been extensively studied in LiB anodes and cathodes using impedance spectroscopy and nuclear magnetic resonance as well as density functional theory (DFT) methods. ${ }^{1-17}$ DFT calculations have provided detailed information on type of dominant ion carriers and their diffusion mechanisms in $\mathrm{LiB} .{ }^{14}$ It was found that $\mathrm{Li}$ diffusion occurs via $\mathrm{Li}$ vacancy in most cathode materials such as $\mathrm{LiCoO}_{2}$ and $\mathrm{LiMnO}_{2}{ }^{15,18,19}$ as well as solid electrolyte materials such as $\mathrm{Li}_{7} \mathrm{La}_{3} \mathrm{Zr}_{2} \mathrm{O}_{12},{ }^{20} \mathrm{Li}_{5} \mathrm{La}_{3} \mathrm{Ta}_{2} \mathrm{O}_{12},{ }^{20}$ and $\mathrm{Li}_{5} \mathrm{La}_{3} \mathrm{Nb}_{2} \mathrm{O}_{12}$, ${ }^{21}$ while it takes place via interstitial $\mathrm{Li}$ in anode materials such as $\mathrm{TiO}_{2}{ }^{22} \mathrm{Li}$ transport via the exchange mechanism (-interstitial $\mathrm{Li}-\mathrm{Li}$ site-interstitial $\mathrm{Li}-$ ) has been reported in solid-electrolyte-interphase materials such as $\mathrm{Li}_{2} \mathrm{CO}_{3}{ }^{14}$ For large-scale applications such as grid-scale storages and electrical vehicles, lithium-sulfur (Li-S) batteries are more promising than $\mathrm{LiB}$ because of their high theoretical energy density $\left(2600 \mathrm{~W} \mathrm{~h} / \mathrm{kg}^{-1}\right.$ (Ref. 23)), environmental friendly features, and low production cost. ${ }^{24}$ During the discharge process, lithium ions react with the sulfur $\left(\mathrm{S}_{8}\right)$ cathode forming intermediate Li-polysulfides and finally crystalline $\mathrm{Li}_{2} \mathrm{~S}^{23,25-28} \mathrm{~S}_{8}$ $\rightarrow \mathrm{Li}_{2} \mathrm{~S}_{8} \rightarrow \mathrm{Li}_{2} \mathrm{~S}_{6} \rightarrow \mathrm{Li}_{2} \mathrm{~S}_{4} \rightarrow \mathrm{Li}_{2} \mathrm{~S}_{2} \rightarrow \mathrm{Li}_{2} \mathrm{~S}$. It is believed that diffusion of $\mathrm{Li}^{+}$in $\mathrm{Li}_{2} \mathrm{~S}$ is slow, and therefore, the formation of $\mathrm{Li}_{2} \mathrm{~S}$ crusts on the surface of sulfur cores during the lithiation process leads to an incomplete conversion of sulfur to $\mathrm{Li}_{2} \mathrm{~S}$. Consequently, the measured discharge capacity is often less than the theoretical value. ${ }^{25}$ Despite the importance of Li$\mathrm{S}$ batteries, formation and diffusion of ions in $\mathrm{Li}_{2} \mathrm{~S}$ have not been studied so far. In this work, we calculated formation energies of possible defects and diffusion mechanism of the most favorable ones in $\mathrm{Li}_{2} \mathrm{~S}$.

\footnotetext{
${ }^{\text {a)} E l e c t r o n i c ~ m a i l: ~ p a y a m . k a g h a z c h i @ f u-b e r l i n . d e ~}$
}

The DFT calculations were performed using the

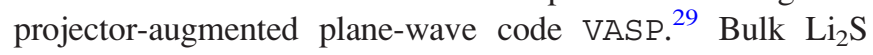
was modelled by $2 \times 2 \times 2$ super cells with $4 \times 4 \times 4$ Monkhorst-Pack $k$-point mesh with an energy cutoff of $360 \mathrm{eV}$. The diffusion pathways were calculated with the Nudge Elastic Band (NEB) method using 8 images. We have calculated the electronic and atomic structures as well as defect formation energies and diffusion barriers using the generalized gradient approximation (GGA) exchange-correlation functional proposed by Perdew, Burke, and Ernzerhof (PBE). ${ }^{30}$

In this work, we have considered the following types of defects: (1) neutral and charged Li vacancy $\left(\mathrm{V}_{\mathrm{Li}}\right.$ and $\left.\mathrm{V}_{\mathrm{Li}}^{-}\right)$, (2) neutral and charged interstitial $\mathrm{Li}\left(\mathrm{Li}\right.$ and $\left.\mathrm{Li}^{+}\right)$, (3) neutral and charged $\mathrm{S}$ vacancy $\left(\mathrm{V}_{\mathrm{S}}\right.$ and $\left.\mathrm{V}_{\mathrm{S}}^{+2}\right)$, (4) neutral and charged interstitial $\mathrm{S}$ (S and $\mathrm{S}^{-2}$ ), (5) neutral Li Frenkel $\left(\mathrm{FR}_{\mathrm{Li}}\right)$, and (6) $\mathrm{Li}_{2} \mathrm{~S}$ Schottky $\left(\mathrm{SC}_{\mathrm{Li}_{2} \mathrm{~S}}\right)$. Formation energies of defects were calculated by

$$
\Delta E_{\mathrm{d}}^{i, q}=E_{\mathrm{tot}}^{i, q}-E_{\mathrm{tot}}^{\mathrm{Li}_{2} \mathrm{~S}}+\sum_{i} n_{i} \mu_{\mathrm{i}}+q\left(\epsilon_{\mathrm{F}}+\epsilon_{\mathrm{VBM}}\right)+\Delta E,
$$

where $E_{\mathrm{tot}}^{i, q}$ and $E_{\mathrm{tot}}^{\mathrm{Li}_{2} \mathrm{~S}}$ are the total energies of defective and pristine $\mathrm{Li}_{2} \mathrm{~S} . n_{i}$ and $\mu_{i}$ are the number and chemical potential of defects ( $\mathrm{Li}$ or $\mathrm{S}$ ). We consider the dependence of the defect formation energy with respect to $\mu_{\mathrm{Li}}$, which is limited to a range within which $\mathrm{Li}_{2} \mathrm{~S}$ is thermodynamically stable with respect to bulk $\mathrm{Li}$ and $\mathrm{S}$. Li crystal would start to form at the surface of $\mathrm{Li}_{2} \mathrm{~S}$ if $\mu_{\mathrm{Li}}$ becomes too high (i.e., Li-rich limit). Moreover, since we are interested in $\Delta E_{\mathrm{d}}^{i, q}$ as function of (half) cell voltage, we choose the zero value of $\mu_{\mathrm{Li}}$ to be the chemical potential of Li-rich limit and define

$$
\Delta \mu_{\mathrm{Li}}=\mu_{\mathrm{Li}}-\mu_{\mathrm{Li}}^{\text {rich }}=\mu_{\mathrm{Li}}-E_{\mathrm{Li}}^{\text {bulk }},
$$

and obtain the (half) cell voltage with respect to Li electrode by 


$$
U=-\frac{\Delta \mu_{L i}}{e},
$$

where $E_{\mathrm{Li}}^{\text {bulk }}$ is the total energy per atom of bulk $\mathrm{Li}$ with a bcc crystal structure (metal Li). Moreover, $\Delta \mu_{\mathrm{Li}}$ cannot be lower than a Li-poor limit below which $\mathrm{Li}_{2} \mathrm{~S}$ decomposes to sulfur. Therefore, in the defect formation energy plot, we also excluded the chemical potentials smaller than $\mu_{\mathrm{Li}}^{\text {poor }}$ $=\frac{1}{2}\left(\Delta G_{\mathrm{Li}_{2} \mathrm{~S}}^{\mathrm{bulk}}\right)$ (half of the Gibbs free energy formation of bulk $\mathrm{Li}_{2} \mathrm{~S}$ ). Our theoretical value of $\mu_{\mathrm{Li}}^{\text {poor }}=2.01 \mathrm{eV}$ is $0.28 \mathrm{eV}$ lower than the experimental value of $\mu_{\mathrm{Li}}^{\text {poor }}=2.29 \mathrm{eV}\left(\Delta G_{\mathrm{Li}_{2} \mathrm{~S}}^{\text {bulk }}\right.$ $\approx-4.58 \mathrm{eV}$ (Ref. 31)), which can be mainly because of using PBE functional and/or due to the fact that the theoretical value has been calculated at $T=0$ and $p=0$, while the experimental value has been measured at $T=298 \mathrm{~K}$ and $p=1 \mathrm{bar}$. In this work, we assume that $\mu_{\mathrm{Li}}$ can change freely between the Li-rich and Li-poor limits but $\mu_{\mathrm{S}}$ has to satisfy this requirement

$$
\mu_{\mathrm{S}}=E_{\mathrm{tot}}^{\mathrm{Li}_{2} \mathrm{~S}}-2 \mu_{\mathrm{Li}},
$$

where $E_{\mathrm{tot}}^{\mathrm{Li} 2 \mathrm{~S}}$ is the total energy per formula unit of bulk $\mathrm{Li}_{2} \mathrm{~S}$.

In Eq. (1), $\epsilon_{F}$ is the Fermi level (the energy of the electron reservoir in $\mathrm{Li}_{2} \mathrm{~S}$ ), referenced to the bulk valence-band maximum $(\mathrm{VBM})$ energy $\left(\epsilon_{\mathrm{VBM}}\right) . \Delta E$ is the correction term to account for the finite-cell size effect of charged defects and also to align the electrostatic potentials of defective and pristine supercells. $\Delta E$ was calculated using the FNV approach $^{32,33}$ with the theoretical value of 3.6 for the dielectric constant. ${ }^{34}$

To calculate $\Delta E_{\mathrm{d}}^{i, q}$ and $\epsilon_{\mathrm{F}}$ as function of $\Delta \mu_{L i}$, we assumed that all possible types of $\mathrm{Li}$ and $\mathrm{S}$ defects with concentrations of $n_{i}$ as well as electrons and holes with concentrations of $n_{e}$ and $n_{h}$, respectively, can exist simultaneously in $\mathrm{Li}_{2} \mathrm{~S}$ and applied the requirement of charge neutrality

$$
\begin{aligned}
& \underbrace{\int_{\mathrm{CBM}}^{\infty} D(\epsilon) f\left(\epsilon, \epsilon_{\mathrm{F}}\right) d \epsilon}_{n_{\mathrm{e}}}-\underbrace{\int_{-\infty}^{\mathrm{VBM}} D(\epsilon)\left[1-f\left(\epsilon, \epsilon_{\mathrm{F}}\right)\right] d \epsilon}_{n_{\mathrm{h}}} \\
& =\sum_{i} q_{i} \underbrace{n_{i}^{0} \exp \left(-\frac{\Delta E_{\mathrm{d}}^{i, q}}{k_{B} T}\right)}_{n_{i}} .
\end{aligned}
$$

In this equation, $D(\epsilon)$ is the density of states, $f\left(\epsilon, \epsilon_{\mathrm{F}}\right)$ is the Fermi-Dirac distribution $f\left(\epsilon, \epsilon_{\mathrm{F}}\right)=\left\{1+\exp \left[\left(\epsilon-\epsilon_{\mathrm{F}}\right) /\right.\right.$ $\left.\left.k_{\mathrm{B}} T\right]\right\}^{-1}, q_{i}$ is the charge state of defect $i . n_{\mathrm{e}}, n_{\mathrm{h}}$, and $n_{\mathrm{i}}$ are the concentration of electrons, holes, and defects of type $i$, while $n_{i}^{0}$ is the maximum possible concentration of defects of type $i$ per unit volume. Since Eqs. (1) and (5) are selfconsistent, $\Delta E_{\mathrm{d}}^{i, q}$ and $\epsilon_{F}$ were calculated iteratively.

Calculated defect formation energy and Fermi energy as function of $\Delta \mu_{L i}$ (Eq. (2)) and $U$ (Eq. (3)) are illustrated in Figs. 1 and 2. It is found that for a wide range of $\Delta \mu_{L i}(U)$, namely, $\quad-2.01 \mathrm{eV} \leq \Delta \mu \leq-0.17 \mathrm{eV} \quad(2.01 \mathrm{~V} \leq U \leq 0.17 \mathrm{~V})$, $\mathrm{Li}^{+1}$ is the most favorable defect type with a formation energy of $1.02 \mathrm{eV}$. At this range of $\mathrm{Li}$ chemical potential (cell voltage), $\mathrm{V}_{\mathrm{Li}}^{-}$is only $0.13 \mathrm{eV}$ less favorable. The reason that the formation energy of charged defects in this range does not change with $\Delta \mu_{L i}$ (or $U$ ) is that increase in the Fermi energy

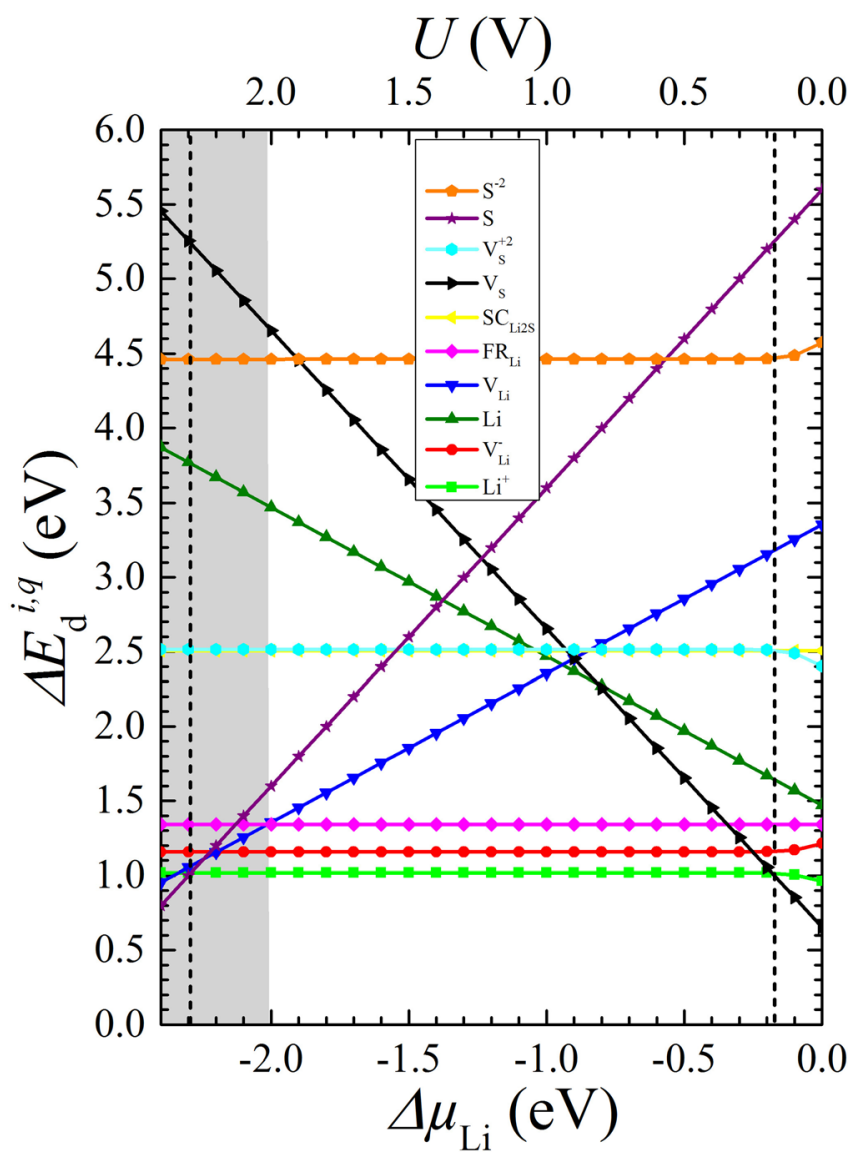

FIG. 1. Formation energies of different types of defects in bulk $\mathrm{Li}_{2} \mathrm{~S}$ as function of $\Delta \mu_{L i}$ and $U$. The chemical potential range of Li-poor limit is shaded in grey.

and chemical potential of $\mathrm{Li}$ are equal and therefore cancel each other (see Eq. (1)). At the high chemical potential (low cell voltage) range of $-0.17 \mathrm{eV} \leq \Delta \mu_{L i} \quad \leq 0.00 \mathrm{eV}$ $(0.17 \mathrm{~V} \leq U \leq 0.00 \mathrm{~V}), \mathrm{V}_{\mathrm{S}}$ becomes the most favorable defect type. At this range, we find a decrease in the formation energy of $\mathrm{Li}^{+1}$ and increase in the formation energy of $\mathrm{V}_{\mathrm{Li}}^{-}$. This result is in line with a smaller increase of Fermi energy (see Fig. 2 and Eq. (1)) with $\Delta \mu_{L i}$ (decrease of $U$ ).

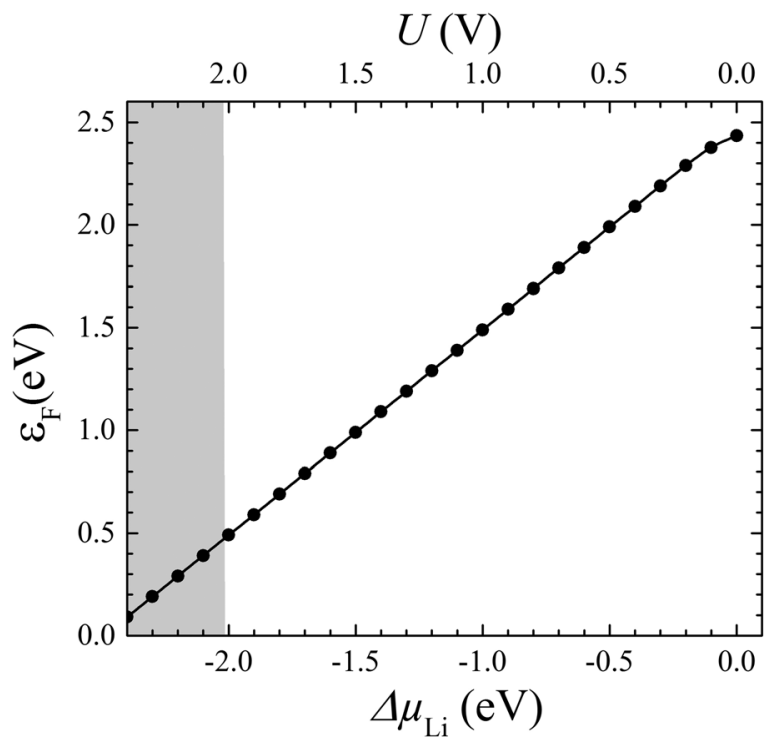

FIG. 2. Fermi energy of defective $\mathrm{Li}_{2} \mathrm{~S}$ as function of $\Delta \mu_{L i}$ and $U$. The chemical potential range of Li-poor limit is shaded in grey. 

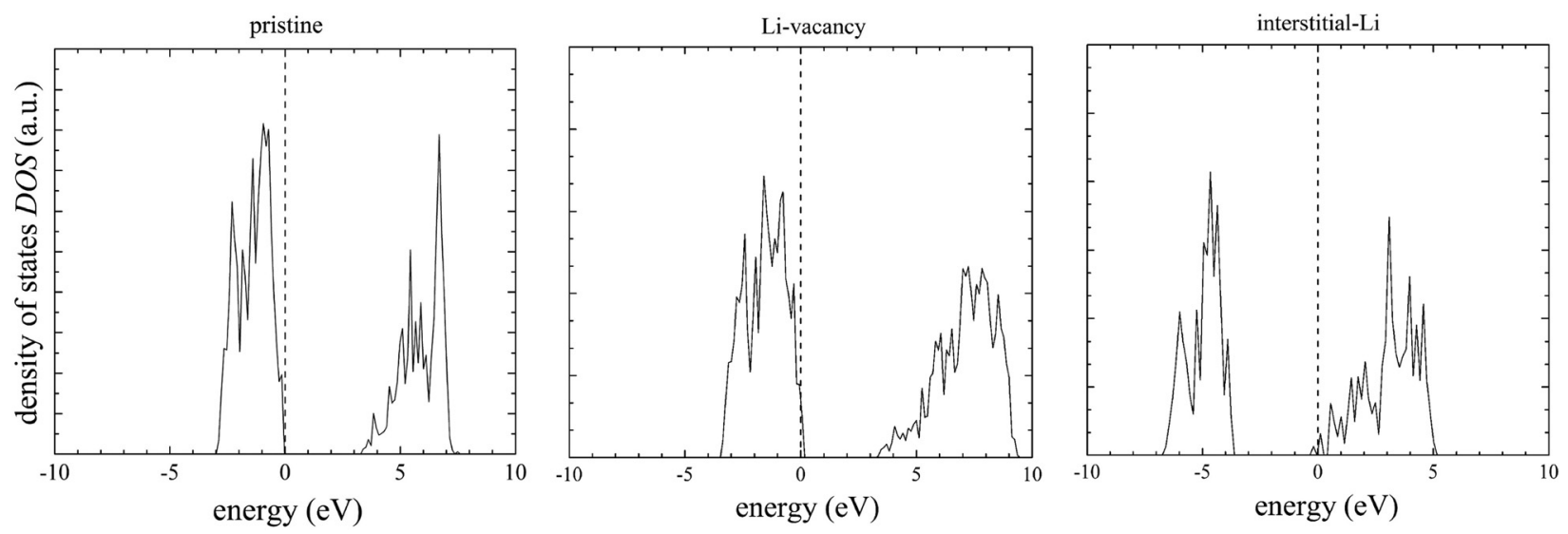

FIG. 3. Total density of states (DOS) of pristine, ( $\mathrm{Li}$ ) vacancy, and interstitial (Li) defective $\mathrm{Li}_{2} \mathrm{~S}$ calculated using GGA-PBE functional. The Fermi energy is set to zero.

The calculated total density of states for pristine as well as neutral vacant and interstitial $\mathrm{Li}$ is presented in Fig. 3. Bulk $\mathrm{Li}_{2} \mathrm{~S}$ is an indirect band gap semiconductor. The GGA-PBE band gap $\left(E_{\mathrm{g}}\right)$ calculated in this work is $3.24 \mathrm{eV}$, which is in agreement with the previous GGAPBE values of $E_{\mathrm{g}} 3.36 \mathrm{eV}$ (Ref. 34) and $E_{\mathrm{g}}=3.29 \mathrm{eV} .{ }^{35} \mathrm{It}$ is known that GGA-PBE functional underestimates the width of band gap. We have not found any experimental measurement of $E_{\mathrm{g}}$ for $\mathrm{Li}_{2} \mathrm{~S}$. To investigate the influence of underestimation of $E_{\mathrm{g}}$ on our results, defect formation energies were calculated for larger values of $E_{\mathrm{g}}$ (up to $4.00 \mathrm{eV}$ ). We found that the underestimation of $E_{\mathrm{g}}$ does not affect the conclusions of this work.

Afterwards, we studied Li diffusion for the following mechanisms:

Li hopping to nearby single and paired Li vacancy sites. For the divacancy mechanism, we have considered orthogonal and diagonal move. Previous studies indicate that the diagonal pathway is the most favorable pathway for Li diffusion in most layered cathode materials in $\mathrm{Li}$-ion batteries such as $\mathrm{LiCoO}_{2}$ and $\mathrm{LiMnO}_{2} \cdot{ }^{15,17}$ However, since $\mathrm{S}^{-2}$ ions are rather large in $\mathrm{Li}_{2} \mathrm{~S}, \mathrm{Li}$ ions that move along the diagonal pathway fall to adjacent vacant sites. Therefore, the diagonal diffusion of $\mathrm{Li}$ to a divacancy in $\mathrm{Li}_{2} \mathrm{~S}$ is unlikely.
The energy barrier $\left(\Delta E_{\mathrm{b}}^{\mathrm{Li}}\right)$ for orthogonal hopping of a $\mathrm{Li}$ to a divacant $\mathrm{Li}$ site $\left(\Delta E_{\mathrm{b}}^{\mathrm{Li}}=0.20 \mathrm{eV}\right)$ is slightly lower than that to a single vacant site $\left(\Delta E_{\mathrm{b}}^{\mathrm{Li}}\right.$ $=0.27 \mathrm{eV}$ ). However, the total energy of a divacancy is $0.20 \mathrm{eV}$ less favorable than two separated single vacancies. Therefore, $\mathrm{Li}$ hopping to a single vacancy is a more favorable mechanism than that to a divacant site (see Fig. 4 (left)).

(ii) Li hopping between interstitial (octahedral) sites and also exchange of Li between interstitial sites and lattice sites. We find that the exchange mechanism (see Fig. 4 (right)) has a diffusion barrier of $\Delta E_{\mathrm{b}}^{\mathrm{Li}}$ $=0.45 \mathrm{eV}$, which is much lower than that of $1.58 \mathrm{eV}$ for Li hopping between interstitial sites (which is not shown in Fig. 4).

Lithiation of a $\mathrm{S}$ cathode is known to start with the formation of $\mathrm{Li}_{2} \mathrm{~S}$ crusts on the outer surfaces of $\mathrm{S}$ particles and continue via a two-phase growth process, ${ }^{36}$ during which nucleation and growth of $\mathrm{Li}_{2} \mathrm{~S}$ occurs at the $\mathrm{Li}_{2} \mathrm{~S} / \mathrm{S}$ interface (see Fig. 5). Thus, the discharge capacity of $\mathrm{S}$ cathodes depends strongly on the activation energy barrier of $\mathrm{Li}$ ion transport within the $\mathrm{Li}_{2} \mathrm{~S}$ crusts, $\Delta E_{\mathrm{a}}^{\mathrm{Li}}=\Delta E_{\mathrm{d}}^{\mathrm{Li}}+\Delta E_{\mathrm{b}}^{\mathrm{Li}}$, which is the sum of formation energy and diffusion barrier. The calculated values of $\Delta E_{\mathrm{a}}^{\mathrm{Li}}$ in $\mathrm{Li}_{2} \mathrm{~S}$ are very high: $1.47 \mathrm{eV}$ and $1.42 \mathrm{eV}$ for $\mathrm{Li}^{+1}$ and $\mathrm{V}_{\mathrm{Li}}^{-}$, respectively.
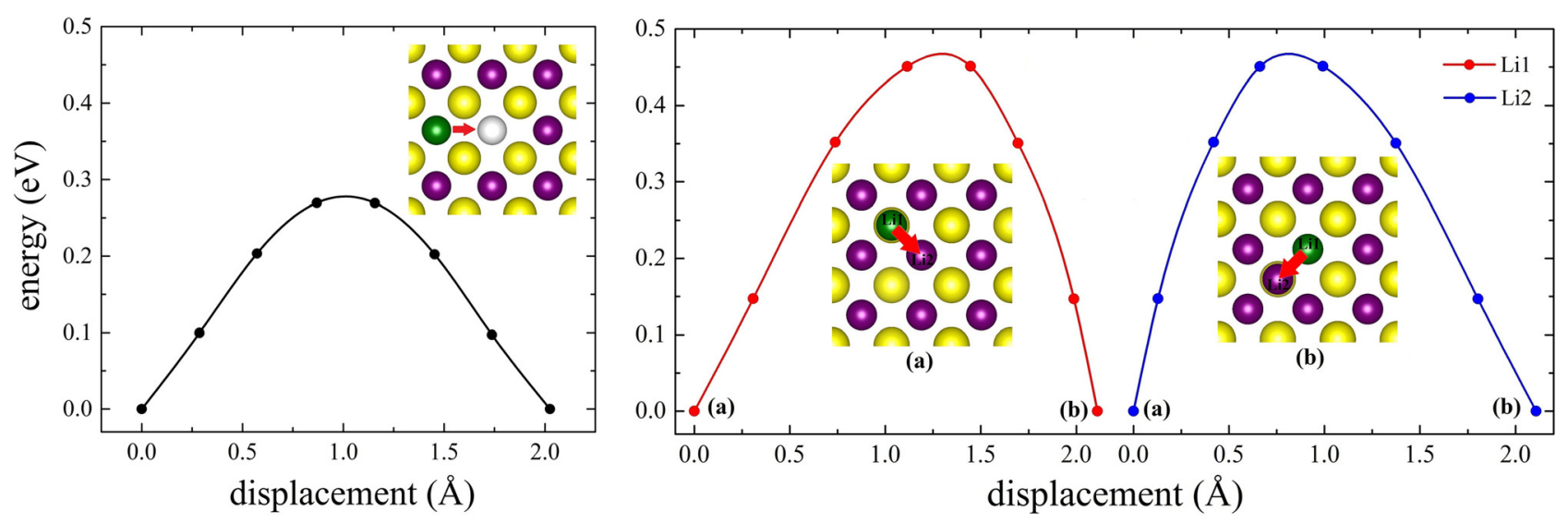

FIG. 4. Energy profiles and atomic structures for diffusion of (left) Li vacancy as well as (right) simultaneous diffusion of interstitial Li1 to Li2 site and Li2 site to the nearby empty interstitial site (exchange mechanism) in $\mathrm{Li}_{2} \mathrm{~S}$. Li atoms are in violet, $\mathrm{S}$ atoms in yellow, diffusing Li atoms in green, and vacant sites in white. 


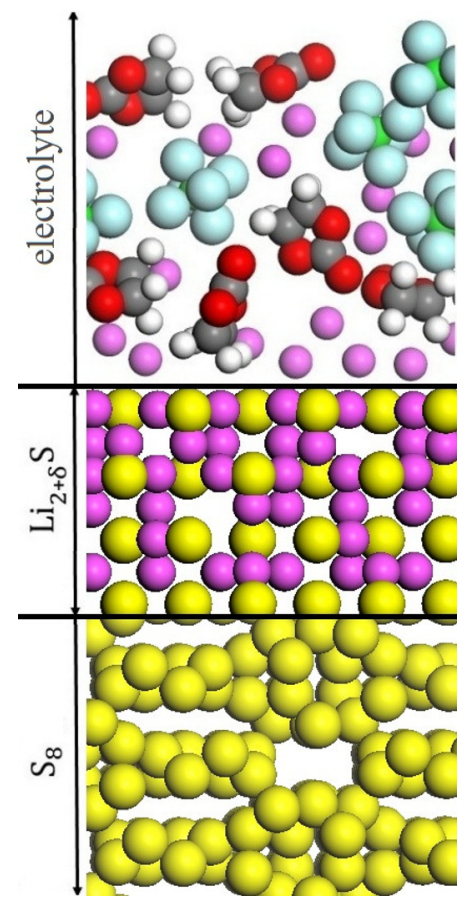

FIG. 5. Schematic of two-phase model for lithiation of sulfur $\left(\alpha-\mathrm{S}_{8}\right)$ during the discharge process in Li-S batteries.

In summary, we have studied thermodynamics and kinetics of defects in $\mathrm{Li}_{2} \mathrm{~S}$ using ab initio calculations. According to the defect formation energy plot, positively charged interstitial $\mathrm{Li}$ is $0.13 \mathrm{eV}$ more favorable than negatively charged $\mathrm{Li}$ vacancy almost for the whole range of cell voltages relevant to Li-S battery, where charge and discharge take place, namely $1.5 \mathrm{~V} \leq U \leq 2.4 \mathrm{~V} .{ }^{37,38}$ However, the diffusion barrier is $0.18 \mathrm{eV}$ lower in the latter case. We found that the activation energy for formation and diffusion of negatively charged $\mathrm{Li}$ vacancy is $0.05 \mathrm{eV}$ lower than the positively charged interstitial $\mathrm{Li}$, which may show a more dominant role of the former defect type in $\mathrm{Li}$ ion conductivity of $\mathrm{Li}_{2} \mathrm{~S}$. Calculated activation energies for $\mathrm{Li}$ transport in $\mathrm{Li}_{2} \mathrm{~S}$ are very high, explaining why the measured discharge capacity is lower than the theoretical value.

The authors gratefully acknowledge support from the "Bundesministerium für Bildung und Forschung" (BMBF), the computing time granted on the Hessian high performance computer "LICHTENBERG" at Technische Universität Darmstadt and Zentraleinrichtung für Datenverarbeitung (ZEDAT) at the Freie Universität Berlin.

${ }^{1}$ H. Buschmann, J. Dölle, S. Berendts, A. Kuhn, P. Bottke, M. Wilkening, P. Heitjans, A. Senyshyn, H. Ehrenberg, A. Lotnyk, V. Duppel, L. Kienle, and J. Janek, "Structure and dynamics of the fast lithium ion conductor $\mathrm{Li}_{7} \mathrm{La}_{3} \mathrm{Zr}_{2} \mathrm{O}_{12}$," Phys. Chem. Chem. Phys. 13(43), 19378-19392 (2011).

${ }^{2}$ A. Kuhn, S. Narayanan, L. Spencer, G. Goward, V. Thangadurai, and M. Wilkening, "Li self-diffusion in garnet-type $\mathrm{Li}_{7} \mathrm{La}_{3} \mathrm{Zr}_{2} \mathrm{O}_{12}$ as probed directly by diffusion-induced $7 \mathrm{Li}$ spin-lattice relaxation NMR spectroscopy," Phys. Rev. B 83, 094302 (2011).

${ }^{3}$ L. V. Wüllen, T. Echelmeyer, H. W. Meyer, and D. Wilmer, "The mechanism of $\mathrm{Li}$-ion transport in the garnet $\mathrm{Li}_{5} \mathrm{La}_{3} \mathrm{Nb}_{2} \mathrm{O}_{12}$," Phys. Chem. Chem. Phys. 9, 3298-3303 (2007).

${ }^{4}$ S. P. Ong, V. L. Chevrier, G. Hautier, A. Jain, C. Moore, S. Kim, X. Ma, and G. Ceder, "Voltage, stability and diffusion barrier differences between sodium-ion and lithium-ion intercalation materials," Energy Environ. Sci. 4(9), 3680-3688 (2011).
${ }^{5} \mathrm{H}$. Xia, L. Lu, and G. Ceder, "Li diffusion in $\mathrm{LiCoO}_{2}$ thin films prepared by pulsed laser deposition," J. Power Sources 159, 1422-1427 (2006).

${ }^{6} \mathrm{D}$. Morgan, A. Van der Ven, and G. Ceder, "Li conductivity in $\mathrm{Li}_{x} \mathrm{MPO}_{4}$ $(\mathrm{M}=\mathrm{Mn}, \mathrm{Fe}, \mathrm{Co}, \mathrm{Ni})$ olivine materials," Electrochem. Solid State Lett. 7(2), A30-A32 (2004).

${ }^{7}$ A. Van der Ven, G. Ceder, M. Asta, and P. D. Tepesch, "First-principles theory of ionic diffusion with nondilute carriers," Phys. Rev. B 64(18), 184307-1-184307-17 (2001).

${ }^{8}$ A. Van der Ven and G. Ceder, "Lithium diffusion mechanisms in layered intercalation compounds," J. Power Sources 97-98, 529-531 (2001).

${ }^{9}$ P. Kaghazchi, "Phase-sensitivity of Li intercalation into Sn," J. Phys.: Condens. Matter 25(38), 382204 (2013).

${ }^{10} \mathrm{P}$. Kaghazchi, "Mechanism of Li intercalation into Si," Appl. Phys. Lett. 102, 093901 (2013).

${ }^{11}$ E. Lee and K. A. Persson, "Li absorption and intercalation in single layer graphene and few layer graphene by first principles," Nano Lett. 12(9), 4624-4628 (2012).

${ }^{12}$ A. Dunst, V. Epp, I. Hanzu, S. A. Freunberger, and M. Wilkening, "Shortrange $\mathrm{Li}$ diffusion vs. long-range ionic conduction in nanocrystalline lithium peroxide $\mathrm{Li}_{2} \mathrm{O}_{2}$ the discharge product in lithium-air batteries," Energy Environ. Sci. 7, 2739-2752 (2014).

${ }^{13}$ O. Gerbig, R. Merkle, and J. Maier, "Electron and ion transport in $\mathrm{Li}_{2} \mathrm{O}_{2}$," Adv. Mater. 25, 3129-3133 (2013).

${ }^{14}$ S. Shi, P. Lu, Z. Liu, Y. Qi, L. G. Hector, H. Li, and S. J. Harris, "Direct calculation of Li-ion transport in the solid electrolyte interphase," J. Am. Chem. Soc. 134, 15476-15487 (2012).

${ }^{15}$ A. Moradabadi and P. Kaghazchi, "Mechanism of Li intercalation/deintercalation into/from the surface of $\mathrm{LiCoO}_{2}$," Phys. Chem. Chem. Phys. 17, 22917 (2015).

${ }^{16}$ J. Rohrer, A. Moradabadi, K. Albe, and P. Kaghazchi, "On the origin of anisotropic lithiation of silicon," J. Power Sources 293, 221-227 (2015).

${ }^{17}$ T. Zhang, D. Li, Z. Tao, and J. Chen, "Understanding electrode materials of rechargeable lithium batteries via DFT calculations," Prog. Nat. Sci. 23(3), 256-272 (2013).

${ }^{18}$ A. Van der Ven and G. Ceder, "Lithium diffusion in layered $\mathrm{Li}_{x} \mathrm{CoO}_{2}$," Electrochem. Solid-State Lett. 3, 301 (2000).

${ }^{19}$ D. Kramer and G. Ceder, "Tailoring the morphology of $\mathrm{LiCoO}_{2}$ : A first principles study," Chem. Mater. 21, 3799 (2009).

${ }^{20}$ L. J. Miara, S. P. Ong, Y. Mo, W. D. Richards, Y. Park, J. M. Lee, H. S. Lee, and G. Ceder, "Effect of $\mathrm{Rb}$ and Ta doping on the ionic conductivity and stability of the garnet $\mathrm{Li}_{7+2 x-y}\left(\mathrm{La}_{3-x} \mathrm{Rb}_{x}\right)\left(\mathrm{Zr}_{2-y} \mathrm{Ta}_{y}\right) \mathrm{O}_{12}(0 \leq \mathrm{x} \leq 0.375$, $0 \leq \mathrm{y} \leq 1)$ superionic conductor: A first principles investigation," Chem. Mater. 25, 3048-3055 (2013).

${ }^{21}$ X. Yu, W. Xian-Ping, G. Yun-Xia, H. Jing, Z. Zhong, G. Li-Jun, F. QianFeng, and L. Chang-Song, "Correlation of lithium ionic diffusion with $\mathrm{Nb}$ concentration in $\mathrm{Li}_{7-x} \mathrm{La}_{3} \mathrm{Zr}_{2-x} \mathrm{Nb}_{x} \mathrm{O}_{12}$ evaluated by an internal friction method," Chin. Phys. Lett. 31(1), 016201 (2014).

${ }^{22} \mathrm{M}$. Wagemaker, Structure and Dynamics of Lithium in Anatase $\mathrm{TiO}_{2}$ (Delft University Press, 2003).

${ }^{23}$ L. Chen and L. L. Shaw, "Recent advances in lithium-sulfur batteries," J. Power Sources 267, 770-783 (2014).

${ }^{24} \mathrm{~L}$. Wang, Y. Wang, and Y. Xia, "A high performance lithium-ion sulfur battery based on a $\mathrm{Li}_{2} \mathrm{~S}$ cathode using a dual-phase electrolyte," Energy Environ. Sci. 8, 1551 (2015).

${ }^{25}$ Y. Yang, G. Zheng, and Y. Cui, "Nanostructured sulfur cathodes," Chem. Soc. Rev. 42, 3018 (2013).

${ }^{26} \mathrm{~K}$. Kumaresan, Y. Mikhaylik, and R. E. White, "A mathematical model for a lithium-sulfur cell," J. Electrochem. Soc. 155, A576 (2008).

${ }^{27}$ B. Scrosati, J. Hassoun, and Y. K. Sun, "Lithium-ion batteries. A look into the future," Energy Environ. Sci. 4, 3287 (2011).

${ }^{28}$ P. G. Bruce, S. A. Freunberger, L. J. Hardwick, and J. M. Tarascon, "Li$\mathrm{O}_{2}$ and Li-S batteries with high energy storage," Nat. Mater. 11, 19 (2012).

${ }^{29} \mathrm{G}$. Kresse and J. Furthmüller, "Efficient iterative schemes for $a b$ initio total-energy calculations using a plane-wave basis set," Phys. Rev. B 54, 11169 (1996)

${ }^{30}$ J. P. Perdew, K. Burke, and M. Ernzerhof, "Generalized gradient approximation made simple," Phys. Rev. Lett. 77, 3865 (1996).

${ }^{31}$ D. R. Lide, CRC Handbook of Chemistry and Physics, 87 th ed. (CRC Press, 2006).

${ }^{32}$ C. Freysoldt, J. Neugebauer, and C. G. Van de Walle, "Fully ab initio finite-size corrections for charged-defect supercell calculations," Phys. Rev. Lett. 102, 016402 (2009). 
${ }^{33}$ C. Freysoldt, J. Neugebauer, and C. G. Van de Walle, "Electrostatic interactions between charged defects in supercells," Phys. Status Solidi B 248, 1067-1076 (2011).

${ }^{34}$ H. Khachai, R. Khenata, A. Bouhemadou, A. Haddou, A. H. Reshak, B. Amrani, D. Rached, and B. Soudini, "FP-APW+lo calculations of the electronic and optical properties of alkali metal sulfides under pressure," J. Phys.: Condens. Matter 21, 095404 (2009).

${ }^{35}$ R. D. Eithiraj, G. Jaiganesh, G. Kalpana, and M. Rajagopalan, "First-principles study of electronic structure and ground-state properties of alkalimetal sulfides - $\mathrm{Li}_{2} \mathrm{~S}, \mathrm{Na}_{2} \mathrm{~S}, \mathrm{~K}_{2} \mathrm{~S}$ and $\mathrm{Rb}_{2} \mathrm{~S}$," Phys. Status Solidi B 244, 1337-1346 (2007).
${ }^{36}$ R. Xu, I. Belharouak, X. Zhang, R. Chamoun, C. Yu, Y. Ren, A. Nie, R. Shahbazian-Yassar, J. Lu, J. C. M. Li, and K. Amine, "Insight into sulfur reactions in Li-S batteries," ACS Appl. Mater. Interfaces 6, 21938-21945 (2014).

${ }^{37}$ D. Bresser, S. Passerini, and B. Scrosati, "Recent progress and remaining challenges in sulfur-based lithium secondary batteries - a review," Chem. Commun. 49, 10545-10562 (2013).

${ }^{38}$ G. L. Xu, Q. Wang, J. C. Fang, Y. F. Xu, J. T. Li, L. Huanga, and S. G. Sun, "Tuning the structure and property of nanostructured cathode materials of lithium ion and lithium sulfur batteries," J. Mater. Chem. A 2, 19941-19962 (2014). 